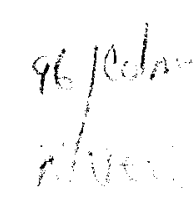

\title{
EMMA SUSANA SPERATTI PIÑERO (1919-1990)
}

Emma Speratti, nacida en Buenos Aires, hizo su formación en la Escuela Normal de Profesores y se dedicó en un principio a la enseñanza secundaria, pero muy pronto se dio maña para sumarse al brillante grupo de estudiosos que capitaneaba Amado Alonso en el Instituto de Filología, donde fue discípula de Pedro Henríquez Ureña y de Raimundo y María Rosa Lida. Mi amistad con ella se inició en enero de 1952, en Madrid, donde los dos estábamos entregados en cuerpo y alma a la investigación. Era una mujer de armazón sólida, muy trabajadora y entusiasta, y de muy buen humor ${ }^{1}$. Allí, en Madrid, me comunicó su deseo de venir a México: por una parte, sentía que el mundo se le cerraba en Buenos Aires (casi todos sus maestros y colegas habían emigrado); por otra, quería conocer este país donde don Ramón del ValleInclán, objeto de sus estudiosos afanes, había estado en dos ocasiones. Y muy pronto se le cumplió su deseo. El Colegio de México le ofreció una beca (muy modesta), y Emma abandonó para siempre su patria. En 1953 se trasladó a México con sólo dos maletas: en una su ropa y sus cosas, y en la otra, la más panzuda, sus libros y papeles.

1 Era algo "morocha", como dicen los argentinos. Julio Cortázar, amigo suyo, le decía "la Negra de Flores" (por el barrio de Buenos Aires en que vivía). Yo también le hacía bromas. Recordando que María Rosa Lida se ufanaba de que su nombre de casada, "María Rosa Lida de Malkiel", era un perfecto endecasílabo agudo - de acentuación análoga a la de "Amor, Amor, un hábito vestí"-, le decía a Emma que el suyo, "Emma Susana Speratti Piñero", era un perfecto endecasílabo de gaita gallega - análogo a "Tanto bailé con el ama del cura" - , y le proponía que se añadiera un tercer apellido para formar un perfectísimo hexámetro dactílico: "Émma Susána Sperátti Piñéro y Beláusteguigóitia" = "Ínclitas rázas ubérrimas, sángre de Hispánia fecúnda". Ella gozaba con esas bromas. 
Los doce años de México (1953-1965) fueron notablemente fecundos: de los 78 números que comprende la lista de sus publicaciones, 55 corresponden a la etapa mexicana. En 1955 obtuvo en la Universidad Nacional Autónoma, summa cum laude, el título de Doctora en Letras con una tesis que luego se convirtió en el libro de 1957, La elaboración artística en "Tirano Banderas". Aparte de las tareas que realizaba en El Colegio de México, tuvo muchos otros quehaceres: fue profesora de literatura en el Mexico City College, ahora Universidad de las Américas; tradujo, pro pane lucrando, seis libros del inglés y del francés, comenzando con Los rollos del Mar Muerto de Edmund Wilson. Alternaba sus estudios eruditos - por ejemplo las "crono-bibliografías" de Horacio Quiroga y de Pedro Henríquez Ureña- con notas críticas de palpitante actualidad. Se interesó mucho en la literatura femenina (Rosario Castellanos, Concha Urquiza, Ángela Figuera, Josefina Vicens, Elena Garro). Su "Carta abierta a Carlos Fuentes", publicada en abril de 1958, fue la primera reseña que tuvo La re'gión más transparente ${ }^{2}$. Y en una época en que nadie se acordaba de Cortázar, autodesterrado y silencioso en París, fue ella quien movió los hilos necesarios para que Juan José Arreola editara en la colección "Los Presentes" su segundo libro de cuentos, Final del juego. La sensibilidad estética de Emma estaba afinada preponderantemente con lo moderno, y no sólo en el ámbito de la literatura, sino también en el del teatro y del cine, en el de la ópera

${ }^{2}$ Voy a citar frases de esta reseña para dar idea de la seguridad y el desparpajo con que hablaba Emma Speratti. Los cuentos de Los días enmascarados -el primer libro de Fuentes- le habían gustado, pero los "anticipos" de $L a$ región más transparente, aparecidos en revistas y en suplementos literarios, la decepcionaron: "Testigos hay de todo lo que dije para desfogar lo que se iba convirtiendo en franca desilusión". Pues bien, ahora, "al leer por fin tu libro, veo, compruebo, que me había equivocado. Y me alegro". Tras lo cual vienen los reparos críticos. Condena Emma "el procedimiento reiterativo" ("Hacia la mitad del libro ya sabemos qué va a ocurrir cuando Ixca Cienfuegos se presenta ante un personaje o golpea a su puerta") y el excesivo afán por lograr imágenes ("A veces aciertas...; otras [imágenes] son francamente innecesarias; en otras, por fin, se te va la mano"); critica también ciertas inseguridades lingüísticas de Fuentes (por ejemplo, su manera de usar el che porteño suscitará en el lector argentino "un convulsivo ataque de risa") y lo pone en guardia contra el pefigro de los "pasajes casi tiernos" ("Cuidado, también. Esa ternura o esa emoción estuvieron muy cerca del despeñadero"). Y concluye: "Fuera de lo señalado, tu novela me parece buena. Siquiera es una novela, y no un guión cinematográfico. Y sobrepasará cómodamente las fronteras de México... Con esto acaban mis elogios. Otros te echarán el incienso. Ojalá no te maree". 
(por ejemplo Gian Cario Menotti), la música (por ejemplo Karlheinz Stockhausen) y la pintura (por ejemplo Remedios Varo). En 1958-59, cuando Tomás Segovia y yo hacíamos la Revista Mexicana de Literatura, fue ella uno de nuestros más asiduos colaboradores ${ }^{3}$.

Deseosa de nuevas aventuras, en 1959 se trasladó Emma a la Universidad Autónoma de San Luis Potosí como profesora "de tiempo completo", y puede decirse que durante algunos años la Facultad de Letras de esa Universidad fue ella. Además de dar sus clases y de seguir escribiendo - diez de sus trabajos llevan un sello de imprenta potosino-, organizó y dirigió un grupo estudiantil de teatro. (No recuerdo qué obras puso en escena, pero sí que una era de García Lorca, quizá La casa de Bernarda Alba.) Desgraciadamente para San Luis Potosí, Emma no se quedó allí tanto tiempo como hubiera sido deseable. En 1964 pasó, siempre como profesora "de tiempo completo", a la muy joven Universidad de Sonora (en Hermosillo), donde puso los cimientos de la Facultad de Letras.

En 1961-62 y en 1963 había estado como "visiting professor", en dos universidades norteamericanas - The Ohio State University y Middlebury College, respectivamente-, y en 1965 se trasladó a Wheaton College (en Norton, Massachusetts), donde permaneció hasta su muerte. En 1973 recibió un diploma de "Outstanding Educator of America”, y con toda razón, pues ella dedicó siempre mucha atención a sus clases. Una beca de la fundación Ford (1969-70) y otra de la fundación Guggenheim (1971-72) le permitieron intensificar sus labores de investigación, de las cuales son fruto sus últimas publicaciones, en particular el segundo y el tercer libro sobre Valle-Inclán y los artículos y el libro sobre Alejo Carpentier. Su estudio sobre "Los brujos en Valle-Inclán" $(N R F H, 1972)$, resultado de varios años de inmersión en lecturas a menudo esotéricas ${ }^{4}$, la dejó bien predispuesta para meterse luego en el mundo de "creencias afro-antillanas" de Carpentier $(N R F H, 1980)$. En los últimos años se dedicó a ver cine en la pan-

${ }^{3}$ La $R M L$ tenía una sección de "palos" anónimos, llamada "La Pajarera". Algunos de ellos proceden de la cáustica pluma de Emma, como este comentario sobre cierta novela llamada Las ganas de creer: "Las ganas de creer - en milagros literarios - son las que se le van esfumando al lector cuando tropieza con novelas como la de..." (y aquí el nombre del apaleado).

${ }^{4}$ La noche del 31 de octubre de 1969 hizo en su casita de Norton una gran fiesta para celebrar con los ritos de Halloween su quincuagésimo cumpleaños, y reunió a buen número de amigos (yo entre ellos). La sala y el estudio, 
talla chica de su casa. Reunió una personalísima filmoteca, hecha de películas de todos los tiempos y lugares, cuidadosamente escogidas. Pero este hedonismo no era pasivo: Emma necesitaba el ejercicio crítico y mantenía una constante comunicación telefónica con Denah Lida (en Cambridge), con Carlos Blanco Aguinaga (en San Diego) y conmigo (en México). (La desgracia era que muchas de las películas que ella comentaba me eran desconocidas.) De esa inmersión en el océano del cine le brotó la idea de una serie de estudios sobre la relación cine-literatura. Escribió sólo el dedicado a Horacio Quiroga (NRFH, 1988). Al morir preparaba otro sobre Julio Cortázar.

No cabe duda de que muchas de las publicaciones de Emma Speratti están destinadas a permanecer. He aquí la lista:

1. "Los americanismos en Tirano Banderas". -Fil, 2 (1950), 225-291.

2. Reseña de: Alonso Zamora Vicente, Las "Sonatas" de Ramón del ValleInclán.-NRFH, 6 (1952), 176-177.

3. "Realidad, mito y elaboración artística en un relato de Ricardo Güiraldes". - BAL, noviembre de 1952, 41-45. [Sobre "El pozo".]

4. "Génesis del esperpento".-BAL, julio de 1953, 5-13.

5. "Acerca de dos fuentes de Tirano Banderas". - NRFH, 7 (1953), 536-550.

6. “Génesis del esperpento".--UMx, 8 (1953-54), núm. 12. [Véase núm. 4.]

7. "Un episodio de Tirano Banderas". - NRFH, 8 (1954), 184-190.

8. “Evolución de Tirano Banderas"',-NRFH, 8 (1954), 389-413.

9. "Dos aspectos de la literatura mexicana del siglo xix: I. Lo histórico y lo antihistórico en Muñoz, visitador de México de Ignacio Rodríguez Galván. II. El teatro neoclásico en la literatura mexicana: Indulgencia para todos de Manuel Eduardo de Gorostiza'. - - RevIb 19 (1954), 321-332.

10. “Las últimas novelas de Valle-Inclán”._CuA, 1954, núm. 6, 250-266.

11. “La expresión de las fuerzas extrañas en Leopoldo Lugones"'.UMx, 9 (1954-55), núm. 7.

hundidos en medrosa penumbra roja, se adornaban con toda clase de paraphernalia de brujería, y en la mesa del comedor había una verdadera exposición bibliográfica de nigromancia y ocultismo. Algunos de los amigos decían en broma -iy hasta un poco en serio! - que Emma estaba estudiando para bruja. La ocurrencia no era, por supuesto, sino una sonriente prueba de cuán en serio tomaba ella sus investigaciones. 
12. "Un relato de Ricardo Güiraldes".-UMx, 9 (1954-55), núm. 9. [Véase núm. 3.]

13. "Hacia una cronología de Horacio Quiroga". - NRFH, 9 (1955), 367-382.

14. Reseña de: Enrique Anderson Imbert, Historia de la literatura hispanoamericana. - NRFH, 9 (1955), 167-169.

15. “El esperpento".-RML, 1 (1955-56), 164-182.

16. "Insistencias temáticas en la obra de Horacio Quiroga". - Antologia M[exico] C[ity] C[ollege], México, 1956, pp. 71-82. [Y traducción inglesa ibid., pp. 301-310.]

17. "Crono-bibliografía de don Pedro Henríquez Ureña".-RevIb, 21 (1956), 195-242.

18. Edición de: Garcilaso Inca, La Florida.-Fondo de Cultura Económica, México, 1956. (Biblioteca americana, 31.)

19. Reseña de: Carmen Bravo Villasante, La mujer vestida de hombre en el teatro español. -NRFH, 10 (1956), 441-442.

20. La elaboración artística en "Tirano Banderas".-El Colegio de México, México, 1957. (Publicaciones de la NRFH, 4.) [Incluye los núms. $1,4,5,7$ y 8 .]

21. En colaboración con Ana María Barrenechea: La literatura fantástica en Argentina.-Imprenta Universitaria, México, 1957.

22. "Acerca de La corte de los milagros". - NRFH, 11 (1957), 343-365.

23. Edición, prólogo y notas de: Domingo Faustino Sarmiento, Facundo.-Imprenta Universitaria, México, 1957. (Nuestros clásicos, 2).

24. "Una fábula moderna, muy antigua". $-R M L, 1957$, núm. 12, 5962. [Sobre The Unicorn, the Gorgon and the Manticore, de Gian Carlo Menotti.]

25. Reseña de: Julio Cortázar, Final del juego.-RML, 1957, núm. 11, 75-76.

26. Reseña de: José Juan Arrom, El teatro de 'Hispanoamérica en la época colonial. - NRFH, 11 (1957), 84-85.

27. Reseña de: Ángel Rosenblat, Buenas y malas palabras en el castellano de Venezuela. - NRFH, 11 (1957), 397-401.

28. Reseña de: Emir Rodríguez Monegal, El juicio de los parricidas.NRFH, 11 (1957), 413-414.

29. Traducción de: Edmund Wilson, Los rollos del Mar Muerto.—Fondo de Cultura Económica, México, 1957. (Breviarios, 124.)

30. Reseña de: Rosario Castellanos, Balún-Canán.-UMx, 12 (1957-58), núm. 5.

31. "Carta abierta a Carlos Fuentes a propósito de su primera novela" [La región más transparente].-UMx, 12 (1957-58), núm. 8.

32. "Ciro Alegría: De La serpiente de oro a El mundo es ancho y ajeno". UMx, 12 (1957-58), núm. 11.

33. "Valle-Inclán y un hai-ku de Basho".-NRFH, 12 (1958), 60-61.

34. "La poesía gauchesca y su parentesco con la poesía popular mexi- 
cana'. - Letras Potosinas (San Luis Potosí), abril-septiembre de 1958, 13-19.

35. "[Manuel José] Othón, cuentista'.-Cuadrante (San Luis Potosí), verano-otoño de 1958, 147-157.

36. "Observaciones sobre La vorágine”' -Estilo (San Luis Potosí), juliodiciembre de 1958, 119-128.

37. Traducción de: Millar Barrows, Los rollos del Mar Muerto.-Fondo de Cultura Económica, México, 1958.

38. "Valle-Inclán y México".-Historia Mexicana, 8 (1958-59), 60-80.

39. "CCómo nació y creció El ruedo ibérico"'.-RML, 1959, núm. 1, 40-48.

40. 'Jorge Luis Borges. - Instituto Potosino de Bellas Artes, San Luis Potosí, 1959. (Jueves literarios, 1).

41. "Paralelo entre Doña Perfecta y La casa de Bernarda Alba". - RUBA, 4 (1959), 369-378.

42. "Génesis y evolución de Sonata de otoño". - RHM, 25 (1959), 57-80.

43. "Los indios y las cartas. Historia y repercusión de un cuentecillo de las crónicas"'.-Rev. de la Fac. de Humanidades (San Luis Potosí), 1 (1959), 41-54.

44. "Temas bíblicos y greco-romanos en la poesía de Concha Urquiza'.-Ibid., 99-115.

45. “Los niños en la obra de Federico García Lorca”. - Ibid., 339-357.

46. "Los últimos cuentos de Horacio Quiroga". - Estilo (San Luis Potosí), abril-junio de 1959, 83-103.

47. Reseña de: Josefina Vicens, El libro vacío. - RML, 1959, núm. 1, 77-78.

48. Reseña de: Ángela Figuera Aymerich, Belleza cruel._Ibid., 81-82.

49. "La frustración en la obra de Federico García Lorca". - Rev. de la Fac. de Humanidades (San Luis Potosí), 2 (1960), 73-94.

50. "El teatro breve de Elena Garro".-Ibid., 333-342.

51. Edición de: Pedro Henríquez Ureña, Obra crítica.-Fondo de Cultura Económica, México, 1960. (Biblioteca americana, 37.) [Incluye, como introducción, el núm. 17.]

52. "Una serie desconocida de Horacio Quiroga: De la vida de nuestros animales".-RML, 1961, núms. 1-4, 39-49.

53. “¿Un nuevo episodio de El ruedo ibérico?”. -NRFH, 15 (1961), $589-604$.

54. Traducción de: Marc Slonim, La literatura rusa.-Fondo de Cultura Económica, México, 1962. (Breviarios, 163.)

55. Traducción de: Norbert Dufourcq, Breve historia de la música.-Fondo de Cultura Económica, México, 1963. (Colección popular, 43.)

56. Traducción de: Michael Harrington, La cultura de la pobreza en los Estados Unidos.-Fondo de Cultura Económica, México, 1963. (Colección popular, 49.)

57. "Los últimos artículos de Valle-Inclán”.-CH(1), 1964, 455-462.

58. Traducción de: T. R. Batten, Las comunidades y su desarrollo.—Fondo 
de Cultura Económica, México, 1964.

59. "Cómo nació y creció El ruedo ibérico". -Íns, 1966, núms. 236/7. [Véase núm. 39.]

60. De "Sonata de otoño" al esperpento. Aspectos del arte de Valle-Inclán.Támesis Books, London, 1968. [Contiene, además de los núms. 10, $22,33,38,39,42,53$ y 57 , tres nuevos estudios: "La farsa de $L a$ cabeza del dragón, pre-esperpento", "Un duende" y "La aventura final de Fernández Vallín".]

61. "Valle-Inclán y México. Parte I: Sonata de estio'”.-Ramón del ValleInclán: An Appraisal of his Life and Works, ed. A. Zahareas et al., Las Américas Publishing Co., New York, 1968, 224-229. [Véase núm. 38.]

62. "La farsa de La cabeza del dragón, pre-esperpento". - Ibid., 374-385. [Véase núm. 60.]

63. "Valle-Inclán y México. Parte II: Tirano Banderas".,-Ibid., 699-710. [Véase núm. 38.]

64. “Los últimos artículos de Valle-Inclán"'-Ibid., 805-812. [Véase núm. 57.]

65. 'El simple y las cartas'’.-Exilio, New York, Spring 1972, 95-106. [Nueva versión del núm. 43.]

66. "Los brujos en Valle-Inclán". - NRFH, 21 (1972), 40-70.

67. El ocultismo en Valle-Inclán.-Támesis Books, London, 1974.

68. "Judas en la obra de Borges"'.-Homenaje al Instituto de Filología y Literaturas Hispánicas "Dr. Amado Alonso" en su cincuentenario (19231973), Buenos Aires, 1975, 401-409.

69. "Julio Cortázar y tres pintores belgas: Ensor, Delvaux, Magritte'. - NRFH, 24 (1975), 541-553, con ilustraciones.

70. En colaboración con Raimundo Lida: "Lacunza en México". RevIb, 44 (1978), 527-533. [Recogido en los Estudios hispánicos de Lida, El Colegio de México, México, 1988, 79-85.]

71. "Noviciado y apoteosis de Ti Noel en El reino de este mundo de Alejo Carpentier"'.-BHi, 80 (1978), 201-228.

72. "Creencias afro-antillanas en El reino de este mundo de Alejo Carpentier'. - NRFH, 29 (1980), 574-596.

73. Pasos hallados en "El reino de este mundo". - El Colegio de México, México, 1981. (Publicaciones del Centro de Estudios Lingüísticos y Literarios, 10.)

74. 'The rose in Borges' works". - Simply a Man of Letters, ed. Carlos Cortínez, University of Maine, 1982, pp. 191-198.

75. "Colón, ¿santo? (Notas sobre El arpa y la sombra de Alejo Carpentier)'. - Sur, Buenos Aires, 1982, núms. 350/1 (Homenaje a María Rosa Lida y a Raimundo Lida), 231-240.

76. "De las fuentes y su utilización en El ahogado más hermoso del mundo".-Homenaje a Ana María Barrenechea, Castalia, Madrid, 1984, 549-555. 
77. 'Cantos y canciones en la obra de Carpentier'.-NRFH, 35 (1987), 515-529.

78. "Horacio Quiroga, precursor de la relación cine-literatura en la América hispánica".-NRFH, 36 (1988), 1239-1249.

Antonio Alatorre

El Colegio de México 